\title{
SMARTI University Model and Performance Benchmarking System UPM
}

\author{
Nguyen Huu Thanh Chung ${ }^{1, *}$, Tran Van Hai ${ }^{1}$, Vu Thi Mai Anh ${ }^{2}$, \\ Nghiem Xuan Huy ${ }^{2}$, Ta Thi Thu Hien², Nguyen Huu Duc ${ }^{2}$ \\ ${ }^{1}$ VNU University of Social Sciences and Humanities, 336 Nguyen Trai, Hanoi, Vietnam \\ ${ }^{2}$ Vietnam National University, Hanoi, 144 Xuan Thuy, Cau Giay, Hanoi, Vietnam
}

Received 10 February 2020

Revised 19 February 2020; Accepted 20 February 2020

\begin{abstract}
In the globalization context, Vietnamese higher education institutions need to fulfill the functions of the third generation university as well as the challenges of the fourth industrial revolution. In this case, the innovation-driven smart university, namely SMARTI model, was proposed. By the approach of the university ecosystem, SMARTI model has been described with 5 core values: digital skills and entrepreneurship; flexibility and connectivity; research and innovation; internationalization; and promotion of social norms. The SMARTI can be governed and benchmarked through the criteria of the university performance metrics (UPM). Preliminary implementations were employed for Vietnam's leading institutions. The results show that these universities have achieved a 5-star standard equivalent to excellent universities in the top 300 in Asia.

Keywords: Smart university, innovation-driven university, SMARTI university model, quality governance and benchmarking, UMP criteria.
\end{abstract}

\footnotetext{
* Corresponding author.

E-mail address: chungnht@vnu.edu.vn
}

https://doi.org/10.25073/2588-1116/vnupam.4212 


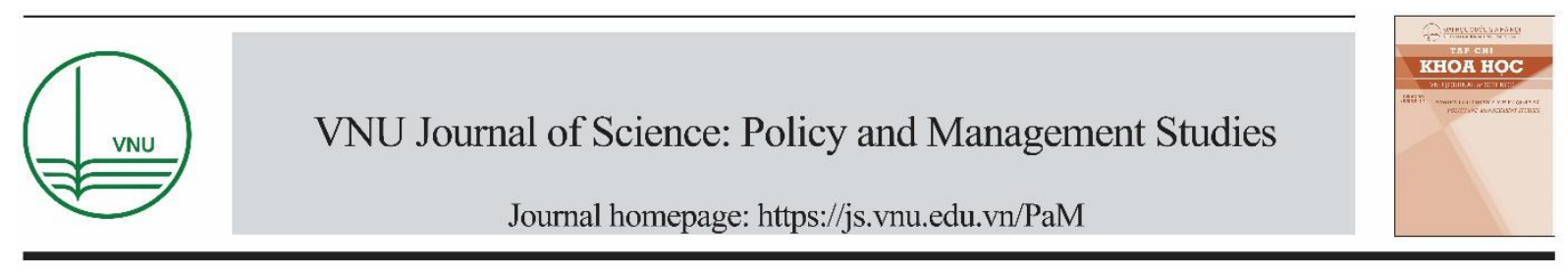

\title{
Mô hình đại học SMARTI và hệ thống đối sánh chất lượng UPM
}

\author{
Nguyễn Hữu Thành Chung ${ }^{1, *}$, Trần Văn Hải ${ }^{1}$, Vũ Thị Mai Anh², \\ Nghiêm Xuân Huy², Tạ Thị Thu Hiền², Nguyễn Hữu Đức ${ }^{2}$ \\ ${ }^{1}$ Truò̀ng Đại học Khoa học Xã hội và Nhân văn, ĐHQGHN, \\ 336 Nguyến Trãi, Hà Nội, Việt Nam \\ ${ }^{2}$ Đại học Quốc gia Hà Nội, 144 Xuân Thủy, Cầu Giấy, Hà Nội, Việt Nam \\ Nhận ngày 10 tháng 02 năm 2020 \\ Chỉnh sửa ngày 19 tháng 02 năm 2020; Chấp nhận đăng ngày 20 tháng 02 năm 2020
}

\begin{abstract}
Tóm tắt: Trong bối cảnh của cuộc cách mạng lần thứ 4 , hệ thống đại học Việt Nam cần đáp ứng hai nhóm yêu cầu thực hiện chức năng của thế hệ đại học thứ 3 và thách thức của cuộc cách mạng này. Đó là mô hình đại học thông minh định hướng đổi mới sáng tạo. Mô hình đại học này đã được mô tả theo tiếp cận hệ sinh thái đại học SMARTI với 5 giá trị cơ bản: kỹ năng số và khởi nghiệp; linh hoạt và liên thông; nghiên cứu và đổi mới sáng tạo; quốc tế hóa và thúc đẩy các chuẩn mực xã hội. Mô hình đại học SMARTI có thể được đối sánh và quản trị thông qua bộ tiêu chuẩn UPM. Kết quả thử nghiệm cho một số cơ sở giáo dục hàng đầu của Việt Nam cho thấy các cơ sở này đã đạt tiêu chuẩn 5 sao tương đương với các đại học xuất sắc trong top 300 châu Á.
\end{abstract}

Tù khóa: Đại học thông minh, Đại học định hướng đổi mới sáng tạo, Mô hình đại học SMARTI, Đối sánh và quản trị chất lượng, Bộ tiêu chuẩn UPM.

\section{Mở đầu}

Ngày nay, cùng với sự phát triển của khoa học dữ liệu, khoa học đo lường và đánh giá chất lượng đại học đã có những bước tiến bộ to lớn, góp phần nhận diện thực tại, phân tích nguyên nhân và quyết định chính sách phát triển. Đo lường và đánh giá chất lượng đã trở thành một công cụ hỗ trợ công tác quản trị đại học, đặc biệt là quản trị chiến lược. Trong đó, xếp hạng đại học (ranking) tập trung đo lường các chỉ số cơ bản (standard metrics), còn đánh giá chất lượng (rating) và kiểm định chất lượng mở rộng thêm cả các chỉ số trung gian (transformal metrics) nên có thể đưa ra kết quả ở mức độ chi tiết và toàn diện hơn. Các chỉ số chất lượng của trường đại học (university performance metrics) tương

\footnotetext{
*Tác giả liên hệ.

Địa chỉ email: chungnht@vnu.edu.vn
}

https://doi.org/10.25073/2588-1116/vnupam.4212 
đương với các chỉ số hiệu suất cơ bản (key performance indicators) sử dụng trong doanh nghiệp [1]. Các công cụ này làm thay đổi hành vi và văn hóa của hệ thống. Mặc dù có một số bất cập, nhưng việc xác định và áp dụng các chỉ số chất lượng sẽ định hướng các hoạt động và gia tăng số lượng và chất lượng các sản phẩm liên quan. Do đó, việc xác định được các chỉ số phù hợp với các chức năng, với sứ mệnh và mục tiêu của đại học và quản trị được các chỉ số đo chúng sẽ tạo ra động lực phát triển tốt cho các cá nhân và tổ chức trong hệ thống.

Trong hai thập kỉ vừa qua, xếp hạng đã trở thành xu thế của thế giới và có ảnh hưởng không nhỏ vào nước ta. Xếp hạng đại học đã góp phần tạo ra động lực thúc đẩy các trường đại học của Việt Nam phát triển theo định hướng nghiên cứu, thúc đẩy công bố quốc tế và kết nối với các bên liên quan. Với việc quản trị tốt các chỉ số cơ bản của xếp hạng, năm 2018, số lượng công bố quốc tế của các cơ sở giáo dục đại học (CSGDĐH) tăng mạnh, góp phần đưa Việt Nam cán mốc gần 10.000 bài/năm, trong đó các CSGDĐH đóng góp tới $70 \%$ [2]. Tuy nhiên, các bảng xếp hạng hiện nay chủ yếu chỉ quan tâm đến các chỉ số nghiên cứu, chưa phản ánh hết các chức năng của các đại học hiện đại, trong đó các hoạt động đổi mới sáng tạo (ĐMST). Đặc biệt, các yếu tố đổi mới, thích ứng với cuộc cách mạng công nghiệp lần thứ tư (CMCN 4.0) chưa được cập nhật.

Trong nghiên cứu gần đây [3], nhóm nghiên cứu đã phân tích các đặc trưng của đại học trong bối cảnh $\mathrm{CMCN} 4.0$ và đưa ra đề xuất ban đầu về bộ tiêu chuẩn đối sánh mức độ thích ứng của đại học 4.0. Cách phân loại và tiếp cận đưa ra trong [3] đã gắn với lịch sử phát triển của các cuộc $\mathrm{CMCN}$ và mức độ gia tăng khả năng "vốn hóa" tri thức. Tuy nhiên, cách mô tả đó phân tích chưa triệt để và rõ ràng việc phân loại đại học và các đặc trưng của thời đại. Đặc biệt, bộ tiêu chí đối sánh chất lượng đại học chưa được thử nghiệm. Một số tiêu chí trong đó phản ánh được đặc trưng và hoạt động của đại học trong bối cảnh CMCN 4.0, nhưng tính khả thi khi thu thập dữ liệu không cao.

Trong công trình này, các đặc trưng và chỉ số chất lượng của đại học, đặc biệt là các CSGDĐH của Việt Nam được phân tích và xác định theo hai nhóm (i) chức năng của đại học thế hệ thứ 3 và (ii) các yêu cầu của $\mathrm{CMCN}$ 4.0. Bộ tiêu chí UPM (University Performance Metrics) đối sánh chất lượng đại học thích ứng với $\mathrm{CMCN} 4.0$ cũng đã được hoàn thiện, các kết quả áp dụng bước đầu theo đánh giá (rating) gắn sao cho một số đại học hàng đầu của Việt Nam cũng được báo cáo.

\section{Thách thức của đại học Việt Nam trong thời kỳ CMCN 4.0}

\subsection{Thách thức với việc xây dựng thế hệ đại học thu' 3}

Trong khi cộng đồng đang có xu hướng xem xét sự phát triển của giáo dục đại học gắn với các yếu tố của khoa học và công nghệ hiện đại gắn với các cuộc $\mathrm{CMCN}$ [4], bài nghiên cứu phân tích sự phát triển của giáo dục đại học theo quan điểm đánh giá mức độ gia tăng giá trị và khả năng "vốn hóa" tri thức đã được đề xuất [5]. Năm 2009, Wissema [5] còn đưa ra sự phân chia lịch sử phát triển đại học theo ba thế hệ. Ông cho rằng, thế hệ đại học thứ nhất ra đời gắn với nhà thờ và giáo hội với vai trò bảo vệ cái đúng, bảo vệ sự thật của vũ trụ. Giáo hội đã đưa ra các quan điểm bị khoa học chối bỏ, ví dụ như hệ thống "địa tâm" lỗi thời. Thời kỳ đó, trường đại học là các nhà thờ, tu viện bằng gạch và vữa, giảng dạy chủ yếu là thuyết trình một chiều bằng ngôn ngữ La-tinh với bảng và phấn. Giáo dục đại học thế giới đã tiến hành cuộc cách mạng học thuật đầu tiên để thúc đẩy và tích hợp hoạt động nghiên cứu trở thành một chức năng học thuật bên cạnh hoạt động giảng dạy. Tuy nhiên, trong thế hệ thứ hai, nghiên cứu khoa học $(\mathrm{NCKH})$ chủ yếu tập trung vào việc khám phá và giải thích các quy luật tự nhiên với tiếp cận đơn ngành, thậm chí là phân chuyên ngành rất hẹp và sâu. Mặc dù đã có tương tác hai chiều giữa giảng viên và sinh viên và thời kỳ cuối đã bắt đầu có sự hỗ trợ của thế hệ máy tính đầu tiên, nhưng chức năng chủ yếu vẫn là truyền thụ kiến thức và nghiên cứu cơ bản. Càng ngày, các CSGDĐH càng được yêu cầu vận hành theo tinh thần khởi nghiệp, thương mại hóa kết quả nghiên cứu và tạo ra các doanh 
nghiệp khởi nghiệp sáng tạo mới [6]. Theo các tổng quan trong [6], các trường đại học đã trải qua một cuộc cách mạng thứ hai để tích hợp việc "vốn hóa" tri thức và phục vụ cộng đồng như một phần nhiệm vụ thứ ba. Các đặc trưng cơ bản của ba thế hệ đại học được tổng kết trên bảng 1 . Các trường đại học không những đã sáng tạo ra nhiều phát minh và sáng chế mới mà còn phát triển hoạt động đổi mới sáng tạo, tạo ra nhiều doanh nghiệp khởi nghiệp sáng tạo, gia tăng giá trị; thực sự trở thành chất xúc tác quan trọng cho sự phát triển kinh tế và xã hội của các khu vực và trên toàn thế giới. Do đó, không chỉ ở châu Âu, mà phần lớn các Chính phủ trên toàn thế giới đã và đang cố gắng hỗ trợ để phát triển nhiều trường đại học theo định hướng đồi mới sáng tạo và khởi nghiệp [6]. Đồng thời với các biện pháp hỗ trợ để tạo môi trường thuận lợi cho các nhà khởi nghiệp trẻ, tinh thần và kỹ năng khởi nghiệp đã được tích hợp vào chương trình đào tạo đại học.

Khái niệm về đại học khởi nghiệp sáng tạo đang được trình bày theo một số cách khác nhau, chưa có sự đồng thuận cao, nhưng về cơ bản có một vài đặc điểm tương đồng phản ánh các đặc điểm cơ bản của mô hình trường đại học này, ví dụ như: có mối quan hệ cao với Chính phủ và doanh nghiệp; hoạt động khởi nghiệp được sự quan tâm của tất cả các thành viên trong trường (các nhà khoa học, giảng viên và sinh viên); quan tâm đến các nguồn vốn mới từ bằng sáng chế, hợp đồng nghiên cứu và tham gia hợp tác với các doanh nghiệp. Đặc biệt, chuyển giao công nghệ được xác định là giải pháp cơ bản để trường đại học "vốn hóa" kết quả nghiên cứu thông qua các dự án thương mại hóa sản phẩm và trường đại học nỗ lực đổi mới cả về phương thức hoạt động và cơ cấu tổ chức để hướng tới "vốn hóa" tri thức [6].

Ở Trung Quốc, đào tạo khởi nghiệp đã được triển khai ở các trường đại học từ đầu những năm 2000 [7]. Malaysia đã chính thức đưa khởi nghiệp thành một trong 10 mục tiêu thay đổi của giáo dục đại học giai đoạn 2015-2025 [8]. Mặc dù đào tạo khởi nghiệp và xây dựng đại học khởi nghiệp sáng tạo là một thách thức lớn với các hệ thống giáo dục còn có nhiều bất cập trong $\mathrm{NCKH}$ và ĐMST, nhưng các trường đại học của Philippines [9] cũng đã đầu tư rất nhiều cho vấn đề này. Các chuyên gia cho rằng giáo dục khởi nghiệp không chỉ có tác động tích cực đối với việc tạo ra các dự án khởi nghiệp mới mà quan trọng còn tạo ra một tâm thế mới cho công dân 4.0 làm chủ bản thân, có đủ năng lực và tự tin nắm bắt các cơ hội mới và biến các cơ hội ấy thành hiện thực trong một tương lai bất định.

Bảng 1. Các chỉ số và đặc trưng của ba thế hệ đại học của thế giới [5].

\begin{tabular}{|c|c|c|c|}
\hline Chỉ số & Thế hệ thứ nhất & Thế hệ thứ hai & Thế hệ thứ ba \\
\hline MụC TIÊU & Truyền thụ tri thức & Đào tạo và nghiên cứu & $\begin{array}{l}\text { Đào tạo và nghiên cứu } \\
\text { Khai phá tri thức }\end{array}$ \\
\hline VAI TRÒ & Bảo vệ sự thật & $\begin{array}{l}\text { Khám phá qui luật tự } \\
\text { nhiên và xã hội }\end{array}$ & Vốn hóa tri thức \\
\hline Đốı TƯợNG & Vũ trụ & Quốc gia & Toàn cầu \\
\hline PHƯơNG PHÁP & $\begin{array}{l}\text { Học giả } \\
\text { Thuyết trình một chiều }\end{array}$ & $\begin{array}{l}\text { Tiếp cận đơn ngành } \\
\text { Tương tác hai chiều }\end{array}$ & $\begin{array}{l}\text { Tiếp cận liên ngành } \\
\text { Tương tác đa chiều }\end{array}$ \\
\hline CÔNG NGHỆ & $\begin{array}{l}\text { Bảng, phấn } \\
\text { Giấy, bút }\end{array}$ & $\begin{array}{l}\text { Trình chiếu } \\
\text { Máy tính, internet }\end{array}$ & $\begin{array}{l}\text { Mobile } \\
\text { Kết nối vạn vật }\end{array}$ \\
\hline KỸ NĂNG Số & Nhập cư số & Bản địa số & Công dân số \\
\hline NGÔN NGỮ & La tinh & Tiếng mẹ đẻ & Tiếng Anh \\
\hline KHUÔN VIÊN & $\begin{array}{l}\text { Nhà thờ, tu viện } \\
\text { Gạch và bê tông }\end{array}$ & $\begin{array}{l}\text { Gạch, bê tông } \\
\text { Nhấp chuột }\end{array}$ & $\begin{array}{l}\text { Network } \\
\text { Hệ sinh thái }\end{array}$ \\
\hline SẢN PHẨM & $\begin{array}{l}\text { Công chức nhà thờ, } \\
\text { nhà nước }\end{array}$ & $\begin{array}{l}\text { Lao động nghề nghiệp } \\
\text { Nghiên cứu và sáng tạo }\end{array}$ & $\begin{array}{l}\text { Lao động nghề nghiệp } \\
\text { Nghiên cứu và sáng tạo } \\
\text { Nhà sáng nghiệp }\end{array}$ \\
\hline
\end{tabular}




\subsection{Thách thức của CMCN 4.0}

Trong thời kỳ $\mathrm{CMCN} 4.0$, giáo dục đại học đang đối mặt một tương lai bất định với các vấn đề sau đây [8]:

(i) Thay đổi xu hướng việc làm và thị trường lao động - các công việc đang tồn tại có thể sẽ lỗi thời trong tương lai và các loại công việc mới sẽ xuất hiện; các mẫu hình công việc, dự án ngắn hạn hoặc bán thời gian trở nên phổ biến. Năng lực học tập suốt đời trở nên cần thiết.

(ii) Thay đổi công nghệ - tuổi thọ của các công nghệ giảm theo cấp số nhân, các công nghệ mới lại xuất hiện nhanh, đòi hỏi phải luôn có sự dự đoán và chuẩn bị các kỹ năng và kiến thức mới, đặc biệt là kiến thức và kỹ năng số.

(iii) Thay đổi cơ hội khởi nghiệp sáng tạo cho mọi người, mọi lĩnh vực và mọi quốc gia nền tảng và hạ tầng công nghệ có tính phổ cập và toàn cầu hóa cao đã được tạo thuận lợi cho cơ hội khởi nghiệp nhỏ và siêu nhỏ với số vốn đầu tư ban đầu không lớn, không cần tư liệu sản xuất và lực lượng lao động nhưng lợi nhuận thu về cao, chỉ cần có kiến thức và kỹ năng khởi nghiệp.

(iv) Thay đổi nhu cầu - thay đổi cách con người sống, làm việc và quan hệ với nhau, cần thiết phải thay đổi các mô hình trong việc giải quyết các yêu cầu mới. Học tập theo đam mê và đào tạo cá thể hóa trở thành một đặc trưng chủ đạo.

(v) Thay đổi hệ thống các giá trị - các cuộc cách mạng công nghiệp chỉ tập trung vào những cải tiến khoa học và do đó dần đến sự phá vỡ hệ thống giá trị tinh thần. Các năng lực nhân văn như trí thông minh xúc cảm, quan tâm, thấu cảm và trách nhiệm xã hội cần thiết được nuôi dưỡng ở mọi giai đoạn học tập. Do đó, giáo dục định huớng và thúc đẩy giá trị xã họi là yếu tố quan trọng để tạo ra những sinh viên tốt nghiệp cân bằng, những người sau này sẽ trở thành thành viên đạo đức của xã hội.

Trước các thách thức đó, giáo dục đại học đang có xu hướng phát triển theo mô hình 4QUAD $[8,10]$. Các đặc trưng của mô hình này được tổng hợp trên bảng 2 và có thể khái quát như sau:
- Mô hình truyền thống (không thay đổi): các trường đại học chọn cách giữ nguyên mô hình "hoạt động như truyền thống", tiếp tục dạy sinh viên một nghề, cấp một văn bằng dựa trên một chương trình đào tạo có tính xác định cao cả về nội dung và thời lượng và hoàn toàn phụ thuộc vào sự hỗ trợ tài chính của Chính phủ. Mô hình đại học bằng gạch và bê tông hiện hữu này có thể phải áp dụng một số thay đổi tối thiểu để duy trì sự tồn tại và cố gắng thích ứng. Một số giải pháp tiếp cận với các bên liên quan và hợp tác với doanh nghiệp sẽ được thực hiện nhưng ít có khả năng bền vững lâu dài; khó đáp ứng các yêu cầu của $\mathrm{CMCN}$ 4.0.

- Mô hình thay đổi biên (đại học jukebox): đây là mô hình đào tạo đa khuôn viên có độ linh hoạt cao, bắt đầu có tính liên thông và đặc trưng đào tạo cá thể hóa; cho phép sinh viên tích lũy tín chỉ trực tiếp và trực tuyến tại các trường đại học trong mạng lưới đối tác; sinh viên được cấp cả văn bằng tốt nghiệp và các chứng chỉ/chứng nhận về học phần mới phù hợp với các yếu tố của CMCN 4.0.

- Mô hình thích úng (đại học uber hóa): Đây là một nền tảng để cung cấp các chương trình cấp bằng phi truyền thống và tăng cường sử dụng các chế độ học tập linh hoạt cho sinh viên, thúc đẩy quá trình học tập suốt đời. Mô hình trường đại học này bắt chước khái niệm dịch vụ giao thông đô thị Uber, cả giảng viên cơ hữu và giảng viên tự do tham gia giảng dạy. Theo đó giáo dục được thúc đẩy bởi nhu cầu, tự điều chỉnh, không rắc rối, rất dễ tiếp cận và thuận tiện.

- Mô hình thay đổi triệt để (mô hình chứng chỉ nano/micro): Đây là mô hình đại học không còn khuôn viên, không còn chương trình đào tạo cho các ngành nghề xác định, sinh viên học tập nền tảng kiến thức và kỹ năng để thỏa mãn bản thân. Mô hình này tổ chức đào tạo cấp các chứng nhận thành phần (nano/micro) thông qua các chương trình đào tạo các tín chỉ phi truyền thống do các tổ chức/cá nhân thực hiện và được cả đại học và doanh nghiệp thừa nhận. Mồ hình đào tạo định hướng doanh nghiệp này đang thu hút sự quan tâm của thế hệ công dân bản địa kỹ thuật số. 
Theo dự đoán [8], các phương pháp dạy và học truyền thống có thể sẽ bị thống trị bởi công nghệ, đổi mới sáng tạo và nhu cầu học tập cá thể hóa. Đến năm 2030, các trường học bằng gạch và bê tông truyền thống có lẽ sẽ chỉ còn tồn tại đối với các lĩnh vực công nghệ kỹ thuật, y học những ngành vẫn liên quan đến thực nghiệm, lâm sàng và các ngành trong lĩnh vực khoa học xã hội khác như giáo dục và nghiên cứu tôn giáo...

Bảng 2. Các mô hình đại học 4-QUAD thích ứng CMCN 4.0 [8]

\begin{tabular}{|c|c|c|c|c|}
\hline TIÊU CHÍ & $\begin{array}{c}\text { Đại học } \\
\text { truyền thống } \\
\text { (Điều chỉnh nhỏ) }\end{array}$ & $\begin{array}{l}\text { Đại học Jukebox } \\
\text { (Thay đổi biên) }\end{array}$ & $\begin{array}{l}\text { Đại học Uber hóa } \\
\text { (Thích nghi) }\end{array}$ & $\begin{array}{l}\text { Đại học } \\
\text { phi truyền thống } \\
\text { (Thay đổi triệt để) }\end{array}$ \\
\hline $\begin{array}{l}\text { ĐộI NGŨ } \\
\text { GIẢNG VIÊN }\end{array}$ & Giảng viên cơ hữu & Giảng viên cơ hữu & $\begin{array}{l}\text { Giảng viên cơ } \\
\text { động và tự do }\end{array}$ & $\begin{array}{l}\text { Giảng viên và } \\
\text { chuyên gia }\end{array}$ \\
\hline $\begin{array}{l}\text { CHƯơ'NG } \\
\text { TRIINH ĐÀO } \\
\text { TẠO }\end{array}$ & $\begin{array}{l}\text { Chương trình xác } \\
\text { định có lựa chọn }\end{array}$ & $\begin{array}{l}\text { Chương trình linh } \\
\text { hoạt đối với sinh } \\
\text { viên }\end{array}$ & $\begin{array}{l}\text { Chương trình linh } \\
\text { hoạt đối với sinh } \\
\text { viên và giảng viên }\end{array}$ & $\begin{array}{l}\text { Chương trình linh } \\
\text { hoạt tối đa; chỉ xác } \\
\text { định về thời lượng, } \\
\text { nội dung hoàn toàn } \\
\text { tự chọn. }\end{array}$ \\
\hline HỌC LIÊU & $\begin{array}{l}\text { Sách và tạp chí } \\
\text { chuyên ngành }\end{array}$ & $\begin{array}{l}\text { Sách, tạp chí, học } \\
\text { liệu điện tử kết } \\
\text { hợp và MOOC } 4.0\end{array}$ & MOOCs 4.0 & $\begin{array}{l}\text { Nội dung do giảng } \\
\text { viên và sinh viên } \\
\text { tạo dựng }\end{array}$ \\
\hline $\begin{array}{l}\text { Nộl DUNG } \\
\text { KIẾN THỨCC }\end{array}$ & $\begin{array}{l}\text { Ngành và chuyên } \\
\text { ngành }\end{array}$ & $\begin{array}{l}\text { Ngành và chuyên } \\
\text { ngành }\end{array}$ & $\begin{array}{l}\text { Liên ngành, thích } \\
\text { ứng, ưu tiên tích } \\
\text { hợp kiến thức xã } \\
\text { hội }\end{array}$ & $\begin{array}{l}\text { Tích hợp các ngành } \\
\text { học, ưu tiên cả kiến } \\
\text { thức và trí tuệ }\end{array}$ \\
\hline SINH VIÊN & $\begin{array}{l}\text { Có khả năng dịch } \\
\text { chuyển nghề } \\
\text { nghiệp }\end{array}$ & $\begin{array}{l}\text { Có khả năng dịch } \\
\text { chuyển nghề } \\
\text { nghiệp }\end{array}$ & $\begin{array}{l}\text { Có khả năng dịch } \\
\text { chuyển nghề } \\
\text { nghiệp và học } \\
\text { tập suốt đời }\end{array}$ & $\begin{array}{l}\text { Học tập suốt đời; tự } \\
\text { bổ túc kiến thức } \\
\text { ngay khi bắt đầu và } \\
\text { vả trong khi làm } \\
\text { nghề. Giáo dục cơ } \\
\text { bản và giáo dục } \\
\text { nâng cao kết hợp }\end{array}$ \\
\hline KHUÔN VIÊN & $\begin{array}{l}\text { Khuôn viên } \\
\text { truyền thống và } \\
\text { Internet }\end{array}$ & $\begin{array}{l}\text { Đa khuôn viên và } \\
\text { Internet }\end{array}$ & $\begin{array}{l}\text { Đa khuôn viên, } \\
\text { trên Internet và ở } \\
\text { doanh nghiệp }\end{array}$ & $\begin{array}{l}\text { Không cần khuôn } \\
\text { viên vật chất, tại } \\
\text { doanh nghiệp và } \\
\text { trên internet }\end{array}$ \\
\hline $\begin{array}{l}\text { MÔ HìNH DẠY } \\
\text { HỌC }\end{array}$ & $\begin{array}{l}\text { Bài giảng, hướng } \\
\text { dẫn, thực hành } \\
\text { phòng thí nghiệm } \\
\text { và studio }\end{array}$ & $\begin{array}{l}\text { Bài giảng, hướng } \\
\text { dẫn, thực hành } \\
\text { phòng thí nghiệm } \\
\text { và studio }\end{array}$ & $\begin{array}{l}\text { MOOCs 4.0, các } \\
\text { khóa học theo } \\
\text { yêu cầu }\end{array}$ & $\begin{array}{l}\text { Bài giảng trực } \\
\text { tuyến, dạy đồng } \\
\text { cấp, sinh viên đồng } \\
\text { sáng tạo các khoá } \\
\text { học mở. MOOCs } 4.0\end{array}$ \\
\hline $\begin{array}{l}\text { KẾT QUẢ HỌC } \\
\text { TậP }\end{array}$ & $\begin{array}{l}\text { Bằng cấp và } \\
\text { chứng chỉ học } \\
\text { thuật }\end{array}$ & $\begin{array}{l}\text { Bằng cấp và } \\
\text { chứng chỉ học } \\
\text { thuật }\end{array}$ & $\begin{array}{l}\text { Bằng cấp và } \\
\text { chứng chỉ học } \\
\text { thuật từ nhiều } \\
\text { trường đại học. } \\
\text { Hồ sơ điện tử }\end{array}$ & $\begin{array}{l}\text { Tập hợp các chứng } \\
\text { chỉ do nhiều bên } \\
\text { liên quan (đại học, } \\
\text { doanh nghiệp) cấp. } \\
\text { Hồ sơ điện tử }\end{array}$ \\
\hline
\end{tabular}




\section{3. Đề xuất mô hình đại học thích ứng $\mathrm{CMCN}$ 4.0 của Việt Nam}

Đối với các quốc gia phát triển, hệ thống giáo dục đại học đã tham gia vào thế hệ thứ ba từ lâu, nền tảng và thành tựu về nghiên cứu, đổi mới sáng tạo và phục vụ cộng đồng đã được xác định. Quá trình chuyển sang thời kỳ $\mathrm{CMCN} 4.0$ diễn ra một cách cách liên tục, chủ yếu là để đổi mới công nghệ và mô hình dạy - học. Mô hình 4QUAD vừa nêu ở trên cũng phán ánh điều đó. Đối với Việt Nam, giáo dục đại học trước hết phải thích ứng với sự phát triển của thế hệ thứ 3 , đồng thời đáp ứng với cả các yêu cầu của $\mathrm{CMCN}$ 4.0. Đại học thế hệ thứ 3 là đại học khởi nghiệp sáng tạo, tập trung đào tạo và vốn hóa tri thức, gia tăng giá trị, còn công nghệ 4.0 thì hỗ trợ tạo điều kiện để triển khai các hoạt động dạy - học thông minh. Trên cơ sở đó, mô hình đại thông minh định hướng đổi mới sáng tạo đã được đề xuất ở Việt Nam [3]. Trong đó thành tố đổi mới sáng tạo và khởi nghiệp là triết lý, mục tiêu và phương thức tạo ra giá trị gia tăng; còn thành tố thông minh là phương thức và điều kiện tổ chức thực hiện dựa vào các tiến bộ của công nghệ 4.0. Các đặc trưng cơ bản của mô hình đại học thông minh định hướng đổi mới sáng tạo được mô tả trong mô hình " 543 ", bao gồm: đào tạo định hướng khởi nghiệp (mô hình 5 trong 1); nghiên cứu hàn lâm định hướng đổi mới sáng tạo; hệ sinh thái đổi mới sáng tạo (mô hình 4 trong 1); đại học thông minh với hệ thống kết nối thực ảo; cơ chế vận hành (mô hình 3 trong 1); mức độ quốc tế hóa và trách nhiệm cộng đồng. Một sự vào cuộc đồng bộ như vậy vừa đáp ứng với nhưng cũng vừa có khả năng dẫn dắt cuộc CMCN ấy.

Mô hình đại học thông minh định hướng đổi mới sáng tạo đề xuất trong [3] có thể được phát triển và khái quát thành mô hình SMARTI sử dụng các chữ cái tiếng Anh để mô tả nội hàm bằng ngôn ngữ Việt. Trong đó, đào tạo được mô tả gọn với mô hình SMART và hệ sinh thái đại học được mô tả qua mô hình 5I (bảng 3). Cụ thể được trình bày dưới đây.

\section{1. Đào tạo - mô hình SMART}

Mô hình SMARTI mô tả cả các hoạt động đào tạo và hệ sinh thái đại học đổi mới sáng tạo. Các nội dung về đào tạo bao gồm: mục tiêu và chuẩn đầu ra, $\mathrm{CTÐT}$, phương pháp dạy - học và phương pháp kiểm tra đánh giá.

- Mục tiêu, triết lý giáo duc và chuẩn đầu ra được phản ánh với 4 chữ $\mathrm{S}$, bao gồm: học tập Suốt đời, kỹ năng Số, khởi nghiệp (Start-up) hướng tới các doanh nghiệp nhỏ (siêu nhỏ) và vừa $(S S M E)$. Mục tiêu này đáp ứng các thách thức (i-iii) nêu trong phần 2.1.

Bảng 3. Mô hình đại học SMARTI thích ứng $\mathrm{CMCN} 4.0$

\begin{tabular}{l|c|l|}
\hline Chuẩn đầu ra & S & Học tập Suốt đời; Số; Start-up; SSME \\
\hline $\begin{array}{l}\text { Chương trình } \\
\text { đào tạo }\end{array}$ & M & $\begin{array}{l}\text { Mở, liên ngành, liên thông, linh hoạt và } \\
\text { trái nghiệm }\end{array}$ \\
\hline \multirow{2}{*}{ Dạy- học } & A & Áo - Đại học thông minh, hạ tầng số \\
\cline { 2 - 3 } & R & Riêng - Đào tạo cá thể hóa \\
\hline \multirow{2}{*}{ Đánh giá } & T & $\begin{array}{l}\text { Thi (Kiến thức, Thái đô, Kỹ năng, Thói } \\
\text { quen và Năng lực khởi nghiệp - KASHE) }\end{array}$ \\
\hline $\begin{array}{l}\text { Hệ sinh thái } \\
\text { đối mới sáng } \\
\text { tạo }\end{array}$ & I & $\begin{array}{l}\text { 5I (ISI, IP, Innovation, Industry, } \\
\text { Internationalization) }\end{array}$ \\
\hline
\end{tabular}


Đây cũng là các nội dung đã được phản ánh trong Luật Giáo dục đại học, Nghị quyết 52/NQTW của Bộ Chính trị về "Một số chủ trương, chính sách chủ động tham gia cuộc Cách mạng công nghiệp lần thứ tư”, Chỉ thị số 16/CT-TTg của Thủ tướng về "Tăng cường năng lực tiếp cận cuộc Cách mạng Công nghiệp lần thứ 4", Quyết định số 1982/QĐ-TTg của Thủ tướng Chính phủ về "Khung trình độ quốc gia Việt Nam", Quyết định số 844/QĐ-TTg của Thủ tướng Chính phủ phê duyệt Đề án "Hô̂ trợ hệ sinh thái khởi nghiệp đổi mới sáng tạo quốc gia đến năm 2025 " và Quyết định số 1665/QĐ-TTg Phê duyệt Đề án "Hỗ trợ học sinh, sinh viên khởi nghiệp đến năm 2025".

- Chuoong trình đào tạo: được đặc trưng với

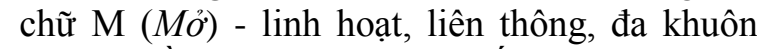
viên, là nền tảng của lộ trình tiến tới đào tạo đại học không bằng cấp với vai trò của doanh nghiệp và các bên liên quan ngày càng cao.

- Phuoong pháp dạy và hoc: được khái quát

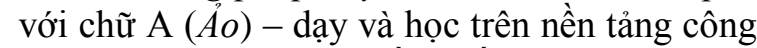
nghệ thông minh và hạ tầng số; $\mathrm{R}$ (Riêng) - đào tạo cá thể hóa.

- Phuoong pháp kiểm tra, đánh giá: T (Thi) phải đánh giá được cả kiến thức, thái độ, kỹ năng, thói quen và kỹ năng khởi nghiệp (KASHE), trong đó có cả các kỹ năng nhân văn và trách nhiệm xã hội.

Theo mô hình này, trong khi triển khai thực hiện Khung trình độ quốc gia, phát triển các chương trình đào tạo mới gắn với $\mathrm{CMCN} 4.0$, đào tạo định hướng khởi nghiệp cần thúc đẩy ngay các hoạt động điều chỉnh chuẩn đầu ra, cập nhật các học phần mới phù hợp với chuẩn đầu ra của các chương trình đào tạo truyền thống. Trong đó, các yêu cầu căn bản, khả thi và có thể triển khai được ngay là đổi mới học phần Tin học cơ sở thành môn học "Giới thiệu CNTT và Kỹ năng số"; bổ sung môn học về "Kỹ năng Khởi nghiệp" và tăng cường học kỳ doanh nghiệp... Đồng thời, đào tạo phải hướng đến tính mở, liên ngành, liên thông giữa các khoa, các trường, trong khu vực và đặc biệt phải gắn với học kỳ doanh nghiệp. Trong tất cả các kỹ năng mà đại học 4.0 hướng tới, có thể xem kỹ năng khởi nghiệp là cơ quản và trọng tâm nhất. Ngoài việc bồi dưỡng tinh thần khởi nghiệp sáng tạo, triển khai động lực phát triển của quốc gia, kỹ năng này còn tạo cơ sở để hình thành tâm thế sẵn sàng thích ứng, nắm bắt và triển khai các thời cơ cho các công dân 4.0.

\subsection{Hệ sinh thái đại học đổi mói sáng tạo - mô hinh $5 I$}

Hoạt động nghiên cứu phải hướng đến công bố quốc tế chất lượng cao (bài báo ISI), sở hữu trí tuệ (IP); phải triển khai các hoạt động đổi mới sáng tạo (Innovation), gắn với công nghiệp (Industry) và mức độ quốc tế hóa cao (Intenationalization). Các hoạt động này phải được triển khai toàn diện và đồng bộ. NCKH cần được đánh cả về năng suất và chất lượng dựa trên hệ thống CSDL tích hợp trong nước và quốc tế. Đặc điểm của đại học 4.0 là thúc đẩy thực thi tri thức, phát triển sản phẩm và vốn hóa tri thức. Vì vậy, các hoạt động và chỉ số về sở hữu trí tuệ, hợp tác doanh nghiệp, kinh phí hợp tác doanh nghiệp, số lượng doanh nghiệp spin-off phải được đề cao. Trong hệ sinh thái đại học đổi mới sáng tạo, cơ sở vật chất và môi trường không chỉ phục vụ các các hoạt động đào tạo và $\mathrm{NCKH}$ truyền thống mà cần thúc đẩy khởi nghiệp, cần có không gian hỗ trợ khởi nghiệp, không gian sáng tạo, vườn ương doanh nghiệp... Đấy còn là một hệ sinh thái thông minh được mô tả, thiết kế và đo lường bằng mô hình $5 \mathrm{C}$ (Connection - kết nối thông tin, Conversion - chuyển đổi thông tin, Cyber - phân tích, Cognition - nhận diện và Configuration - cấu hình hóa) [11], trong đó, các CSGDĐH Việt Nam cần bắt đầu bằng các hoạt động và quản trị, giám sát thông qua các chỉ số cơ bản nhất. Trong thời kỳ $\mathrm{CMCN} 4.0$, ngoài các nội hàm truyền thống, chức năng phục vụ cộng đồng cần quan tâm đển các hoạt động hỗ trợ học tập suốt đời cho cộng đồng, thúc đây phát triển bền vững, phát triển các chuẩn mực và giá trị xã hội.

Trên hết và quan trọng nhất, các nội dung liên quan đến định hướng đổi mới sáng tạo và khởi nghiệp, đại học thông minh đã nêu ở trên phải được thể hiên rõ trong chiến lược phát triển của các CSGDĐT, phản ánh được sứ mệnh, tầm nhìn, mục tiêu và nhiệm vụ, có kế hoạch, 
điều kiện và nguồn lực triển khai phù hợp. Đây là điều kiện tiên quyết và phải được quản trị thường xuyên.

\section{4. Đo lường và đối sánh mức độ thích ứng của trường đại học đối với cuộc CMCN 4.0}

Như đã trình bày, trên tất cả các giải pháp triển khai thực hiện, về mặt quản trị chiến lược, trường đại học phải có tuyên bố và cam kết trong sứ mệnh và chiến lược về mục tiêu đổi mới sáng tạo, có kế hoạch ngắn hạn, trung hạn và các đơn vị, nguồn lực triển khai thực hiện hiệu quả. Đặc biệt, trường đại học phải quản lý được mọi sự thay đổi và tiến bộ của mình. Trong trường hợp này, việc xây dựng bộ tiêu chí đánh giá mức độ thích ứng $\mathrm{CMCN} 4.0$ sẽ rất hữu dụng để các trường tự đối sánh và đưa ra các chính sách đầu tư phù hợp.

\subsection{Bộ tiêu chuẩn - tiêu chí, trọng số và mốc chuẩn}

Các đặc trưng và nội hàm hoạt động của mô hình đại học thông minh định hướng đổi mới sáng tạo đã được mô tả khá chi tiết trong công trình nghiên cứu trước đây của nhóm [3]. Tuy nhiên, giữa việc mô tả và đo lường, đánh giá đặc trưng của đại học luôn có một sự khác biệt nhất định. Trong lúc việc mô tả cần phải đầy đủ cả cơ sở lý luận và nội dung triển khai, việc đánh giá, đối sánh chỉ tập trung vào kết quả và sản phẩm, đặc biệt, chỉ tập trung vào các tham số đo lường và thu thập được cơ sở dữ liệu, thỏa mãn nguyên tắc S.M.A.R.T ( $S$ - specific: tham số cụ thể; $M-$ measurable: định lượng và đo đếm được; $A-$ attainable: khả thi; $R$ - responsible person: có địa chỉ phụ trách và $T$ - time specific: tính kế hoạch). Bên cạnh việc đo lường và đánh giá theo tiếp cận có tính nguyên lý (principle based approach), cũng cần quan tâm đến tính thực tiễn và đảm bảo các quy định của quản lý nhà nước (rules based approach). Đối với Việt Nam, các quy định về hoạt động kiểm định chất lượng và quy định mới đây về tiêu chuẩn của cơ sở giáo dục đại học định hướng nghiên cứu là các yếu tố rất cần được tích hợp vào bộ tiêu chí này.
Để đánh giá và đối sánh chất lượng các hoạt động của CSGDĐH (với các chỉ tiêu chiến lược của mình hoặc/và chỉ báo của các CSGDĐH khác trong và ngoài nước) tiếp cận xếp hạng (ranking) không thể đáp ứng được, vì xếp hạng chỉ dựa vào một số tiêu chí cơ bản và chỉ thực hiện thông qua số liệu. Trong trường hợp này, tiếp cận xếp nhóm và gắn sao (rating) sẽ toàn diện hơn. Thực chất, đối sánh gắn sao rất gần với tiếp cận kiểm định chất lượng, đều được thực hiện với bộ tiêu chuẩn, dựa vào cả trên hồ sơ, minh chứng và thậm chí cả khảo sát hiện trường.

Bộ tiêu chí đánh giá này kết hợp cả hai tiếp cận xếp hạng (đánh giá qua chỉ số) và kiểm định chất lượng (đánh giá qua phân tích minh chứng). Trên cơ sở phân tích các đặc trưng về chất lượng và hiệu quả hoạt động của trường đại học theo bảy đặc trưng đã đề xuất, tham khảo bộ tiêu chí đại học định hướng nghiên cứu đã có của ĐHQGHN [12], tiêu chí xếp hạng nhóm sao (QS STAR) [13], bảng xếp hạng U-multirank (Umultirank 2014) [14], bộ tiêu chí đại học định hướng khởi nghiệp sáng tạo [15] và tiếp cận đảm bảo chất lượng về quản trị chiến lược [16], sau khi thử nghiệm đánh giá cho một số CSGDĐH, Bộ tiêu chuẩn đối sánh mức độ đáp ứng cuộc CMCN 4.0 hay mức đô phát triển của mô hình đại học định hướng đổi mới sáng tạo, 8 tiêu chuẩn và 53 tiêu chí đã được đề xuất, bao gồm:

- Tiêu chuẩn 1: Quản trị chiến lược - 5 tiêu chí, trọng số $6 \%$.

- Tiêu chuẩn 2: Đào tạo - 15 tiêu chí, trọng số $35 \%$. số $20 \%$.

- Tiêu chuẩn 3: Nghiên cứu - 4 tiêu chí, trọng

- Tiêu chuẩn 4: Đổi mới sáng tạo 4 tiêu chí, trọng số $11 \%$.

- Tiêu chuẩn 5: Hệ sinh thái đổi mới sáng tạo - 4 tiêu chí, trọng số 6\%.

- Tiêu chuẩn 6: CNTT và tài nguyên số -10 tiêu chí, trọng số $10 \%$.

- Tiêu chuẩn 7: Mức độ quốc tế hóa - 8 tiêu chí, trọng số $6 \%$.

- Tiêu chuẩn 8: Phục vụ cộng đồng - 3 tiêu chí, trọng số $6 \%$. 
Toàn bộ các tiêu chuẩn và tiêu chí của bộ tiêu chí đối sánh này được trình bày trên bảng 3 và được đặt tên là Bộ tiêu chuẩn UPM (University Performance Metrics).

So sánh với bộ tiêu chí xếp hạng đại học nghiên cứu mà các bảng xếp hạng QS, THE, AWUR và Webometrics, UPM có 10 tiêu chí giống nhau (nhưng chiếm trọng số 34,5\%). Bộ tiêu chuẩn UPM cũng có thêm 19 tiêu chí (chiếm trọng số 34,5\%) đã từng được áp dụng trong các bảng xếp hạng xếp nhóm đại học của QS Star và U-Multirank. Ngoài ra, UPM đã phát triển thêm 24 tiêu chí mới (với trọng số 31\%) liên quan trực tiếp đến các yếu tố của $\mathrm{CMCN} 4.0$, đặc biệt là hoạt động quản trị chiến lược, đào tạo 4.0 , hệ sinh thái đổi mới sáng tạo và khởi nghiệp; quốc tế hóa, phục vụ cộng đồng và hỗ trợ học tập suốt đời (xem bảng 4 ).

Bảng 4. Các tiêu chí và trọng số (ghi trong ngoặc) của bộ tiêu chuẩn UPM

\begin{tabular}{|c|c|c|}
\hline $\begin{array}{l}\text { Nhóm tiêu chí xếp hạng } \\
\text { Đại học định hướng nghiên cứu } \\
\text { (345) }\end{array}$ & $\begin{array}{l}\text { Nhóm tiêu chí xếp nhóm } \\
\text { Đổi mới sáng tạo và Phục vụ } \\
\text { cộng đồng (345) }\end{array}$ & $\begin{array}{l}\text { Nhóm tiêu chí kiểm định } \\
\text { Khởi nghiệp và Công nghệ số } \\
\text { (310) }\end{array}$ \\
\hline \multicolumn{3}{|c|}{ Quản trị chiến lược (60) } \\
\hline & & Chiến lược (15) \\
\hline & & Kế hoạch (10) \\
\hline & & Cơ cấu tổ chức và quản lý (10) \\
\hline & Kiểm định và xếp hạng (10) & Triển khai thực hiện (15) \\
\hline & Dào tạo (350) & \\
\hline & Chất lượng tuyển sinh (40) & Chuẩn đầu ra của CTĐT (15) \\
\hline Quy mô giảng viên (35) & Uy tín giảng viên (35) & Cập nhật CTOT truyền thống (15) \\
\hline Trình độ giảng viên (40) & Quy mô đào tạo SĐH (30) & Phát triển các CTÐT mới (20) \\
\hline \multirow[t]{4}{*}{ Quy mô đào tạo TS (20) } & Hài lòng người học (20) & Tổ chức đào tạo linh hoạt (10) \\
\hline & Hài lòng nhà tuyển dụng (20) & NCKH và dự khởi nghiệp SV (15) \\
\hline & Việc làm của người học (20) & Giải thưởng học thuật của SV (15) \\
\hline & Nghiên cứu (200) & \\
\hline Công bố quốc tế (100) & Giải thưởng KH\&CN (20) & Sách chuyên khảo (20) \\
\hline \multicolumn{3}{|l|}{ Chất lượng nghiên cứu (60) } \\
\hline & Đổi mới sáng tạo (110) & \\
\hline & SHTT trong nước (30) & \\
\hline \multirow[t]{9}{*}{ Kinh phí NCKH \& ĐMST (50) } & SHTT quốc tế (10) & \\
\hline & Doanh nghiệp spin-off (20) & \\
\hline & Hệ sinh thái đổi mới sáng tạo (60) & \\
\hline & & Môi trường R\&D (20) \\
\hline & Đối tác doanh nghiệp (10) & Không gian sáng tạo (20) \\
\hline & & Vườn ươm doanh nghiệp (10) \\
\hline & CNTT và tài nguyên số (100) & \\
\hline & & Kết nối thông tin (10) \\
\hline & Hệ thống Wifi (10) & Quản trị chất lượng (10) \\
\hline \multirow[t]{5}{*}{ Chỉ số Webometrics (10) } & Tương tác trực tuyến (10) & Tài nguyên số (10) \\
\hline & Bài giảng điện tử MOOC (10) & Mức độ sử dụng tài nguyên số (10) \\
\hline & & Ứng dụng hệ thống thực - áo (10) \\
\hline & & Phần mềm kiểm tra trùng lặp (10) \\
\hline & Mức độ quốc tế hóa (60) & \\
\hline SV quốc tế (10) & SV quốc tế trao đổi (5) & Đào tạo bằng tiếng nước ngoài (10) \\
\hline Giảng viên quốc tế (5) & Giảng viên đi trao đổi (5) & Đào tạo liên kết quốc tế (5) \\
\hline \multirow{3}{*}{ Hợp tác quốc tế về nghiên cứu (10) } & & Hội thảo quốc tế (5) \\
\hline & Phục vụ cộng đồng (60) & \\
\hline & Phát triển bền vững (20) & Hỗ trợ học tập suốt đời (20) \\
\hline
\end{tabular}


Trong khoa học đo lường và đánh giá chất lượng giáo dục, trong khi việc xác định các tiêu chí chỉ phụ thuộc một phần vào mục tiêu của bộ công cụ̣, chủ yếu vào khả năng thu thập dữ liệu thì trọng số và mốc chuẩn của các tiêu chí mang tính mục tiêu và chủ quan khá cao, tùy thuộc rất nhiều vào hiện trạng của đối tượng tham gia; định hướng phát triển ưu tiên của các quốc gia. Việc để 10 tiêu chí thuộc nhóm định hướng nghiên cứu với $34,5 \%$ trọng số nhằm thúc đầy quá trình đối sánh quốc tế, làm cơ sở tham gia xếp hạng quốc tế và xây dựng các CSGDĐH định hướng nghiên cứu ở Việt Nam. Thêm vào đó, cũng như quan điểm tiếp cận chung của UPM, các chỉ số cốt lõi, có khả năng đánh giá định lượng với độ chính xác sẽ có trọng số lớn. Còn các tiêu chí thứ yếu, khả năng đánh giá có định tính cao sẽ có trọng số thấp hơn, đảm bảo độ tin cậy chung. Nhóm chỉ số tiếp cận đại học 4.0 cũng có trọng số tương đương $(31 \%)$, thể hiện sự quan tâm đúng mức của UPM đối với sự phát triển đáp ứng $\mathrm{CMCN}$ 4.0.

Về chỉ số và mốc chuẩn, Bộ tiêu chuẩn UPM đã cố gắng bám sát mức chuẩn trung vị của các trường đại học trong top 300 châu Á, ví dụ như các tiêu chí:

- Tỉ lệ giảng viên/sinh viên: xấp xỉ 1:15 (không quy đổi)

- Tỉ lệ giảng viên có trình độ tiến sĩ: $60 \%$

- Số trích dẫn trung bình/bài báo: 8 (từ nguồn Google Scholar)

- Số doanh nghiệp spin-off hình thành trong 5 năm gần nhất: 5 .

Một số chỉ số cũng bám sát quy định của QS star nhưng có điều chỉnh nội hàm để phù hợp tình hình thực tiễn và tính khả thi của Việt Nam như: QS đánh giá kết quả hoạt động đổi mới sáng tạo dựa trên số lượng sáng chế đang hoạt động, nhưng UPM chỉ quy định số lượng sáng chế và giải pháp hữu ích được cấp bằng. Đối tác doanh nghiệp theo quy định của QS star là hợp tác với doanh nghiệp còn có cả sản phẩm đầu ra là các công bố quốc tế, nhưng ở đây UPM quy định mở hơn.

Đặc biệt, để kết hợp với việc đánh giá việc xây dựng các đại học định hướng nghiên cứu của
Việt Nam theo quy định của Nghị định số 99/2019/NĐ-CP của Chính phủ quy định chi tiết và hướng dẫn thi hành một số điều của Luật sửa đổi, bổ sung một số điều của Luật Giáo dục đại học, UPM cũng quy định thêm:

- Tỉ lệ giảng viên có chức danh giáo sư, phó giáo su: $20 \%$

- Tỉ lệ đào tạo sau đại học: $20 \%$

- Số bằng tiến sĩ cấp hàng năm: 20

- Số bài báo trung bình trên giảng viên: 0,3 bài/năm

- Tỉ lệ kinh phí hoạt động khoa học trên tổng nguồn thu: $15 \%$.

\section{2. Đánh giá thử nghiệm}

Sử dụng số liệu xếp hạng quốc tế, số liệu kiểm định chất lượng giáo dục, số liệu CSDL tích hợp về công bố quốc tế Web of Science và Scopus trên hệ thống Vcgate, báo cáo ba công khai, báo cáo thường niên và thông tin trên trang điện tử của các CSGDĐH, UPM có thể đánh giá mức độ đạt chuẩn và gắn sao cho từng tiêu chí, từng tiêu chuẩn và tổng thể. Theo đó, các tiêu chí, tiêu chuẩn và kết tổng thể đạt từ 30-55\% trọng số quy định thuộc nhóm 3 sao; 55-75\% đạt mức 4 sao và trên $75 \%$ trở lên sẽ đạt mức 5 sao. Kết quả thử nghiệm cho 3 CSGDĐH là ĐHQGHN, ĐHQG TpHCM và Trường ĐH Bách khoa Hà Nội được biểu diễn trên hình 1 . Đây là 3 trong 4 CSGDĐH của Việt Nam có tên trong top 300 của bảng xếp hạng QS Châu Á năm 2020 (ĐHQGHN - thứ 147, ĐHQG TpHCM thứ 143 và Trường ĐHBKHN - thứ 261-270) [17-18]. Đồng thời các đơn vị này còn có mặt trong top 1000 thế giới của $\mathrm{QS}$ và $\mathrm{THE}$. Theo đánh giá của UPM, mặc dù một số cơ sở còn có một vài tiêu chuẩn mới đạt chuẩn 4 sao, nhưng xét tổng thể cả 3 CSGDĐH hàng đầu của Việt Nam đều đã có thể gắn chuẩn 5 sao.

Đối với nhóm tiêu chí xếp hạng đại học định hướng nghiên cứu (hình 2), cũng tương tự như đánh giá và đối sánh trực tiếp của bảng xếp hạng QS, so sánh với chuẩn top 300 đại học châu Á, các CSGDĐH hàng đầu vẫn còn có qui mô đào tạo khác cao so với số lượng giảng viên cơ hữu 
hiện có, giảng viên và sinh viên quốc tế còn ít. Theo quy định của NĐ 99/2019 về đại học định hướng nghiên cứu, các đơn vị này đã đạt yêu cầu về số lượng đào tạo và cấp bằng tiến sĩ hàng năm (> 20), số lượng công bố quốc tế và tỉ lệ kinh phí hoạt động KHCN và ĐMST.

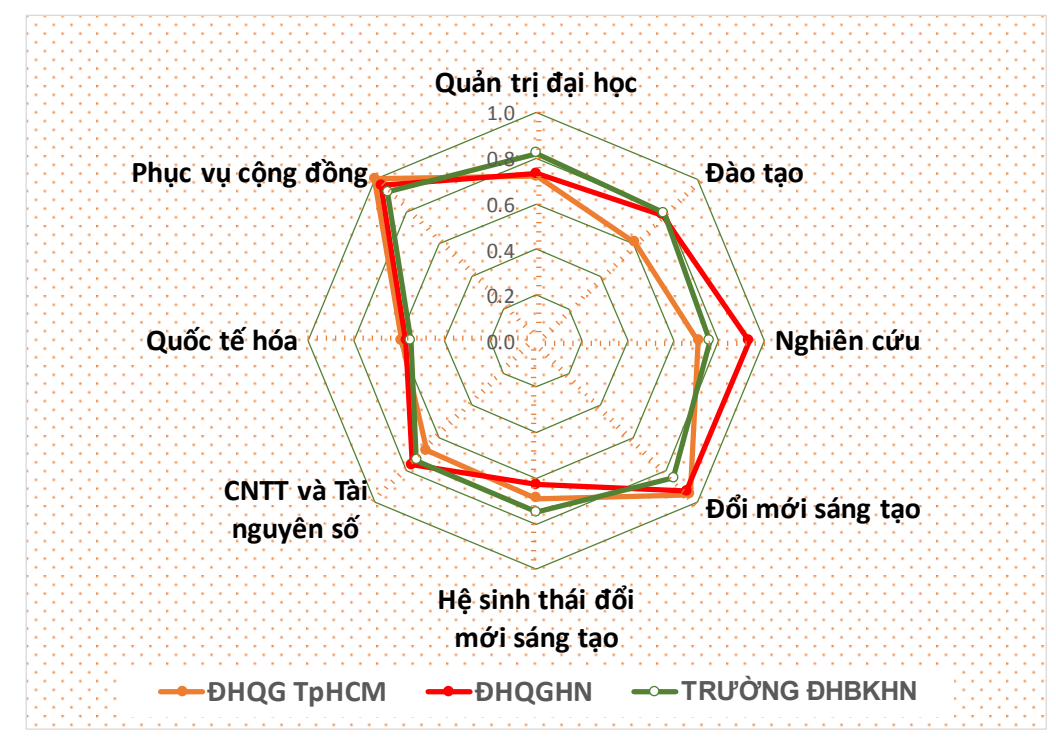

Hình 1. Kết quả đối sánh theo các mốc chuẩn đại học top 300 châu Á đối với các nhóm tiêu chuẩn của Bộ tiêu chí UPM cho ĐHQGHN, ĐHQG TpHCM và Trường ĐHBKHN.

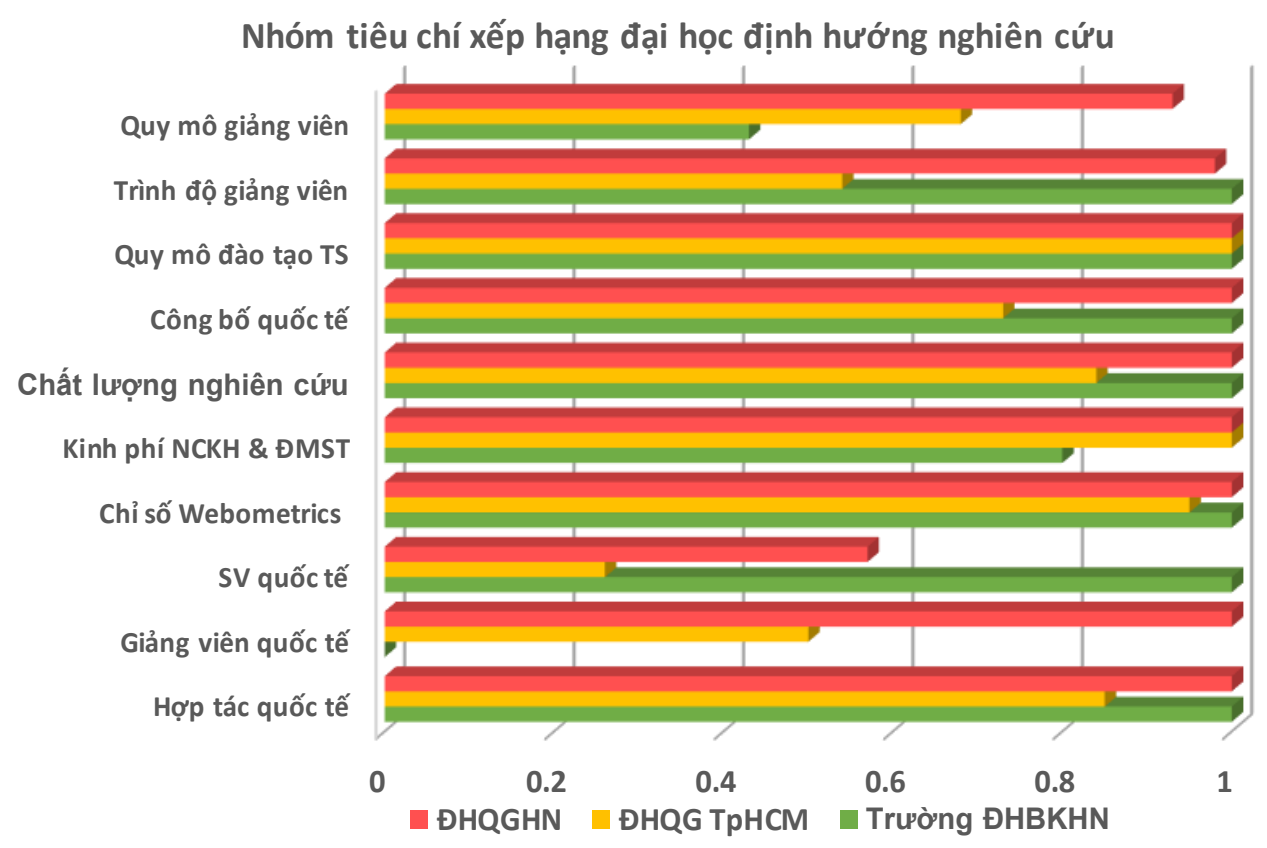

Hình 2. Kết quả đối sánh chuẩn hóa theo các mốc chuẩn đại học top 300 châu Á đối với các nhóm tiêu chuẩn đại học định hướng nghiên cứu của Bộ tiêu chí UPM cho ĐHQGHN, ĐHQG TpHCM và Trường ĐHBKHN. 
Đối với nhóm tiêu chí xếp nhóm đại học (hình 3 ) cho các hoạt động đổi mới sáng tạo và phục vụ cộng đồng, nhận thấy rằng các CSGDĐH hàng đầu này đã quan tâm đúng mực đến công tác kiểm định và xếp hạng và thúc đẩy các chuẩn mực xã hội. Đây là các CSGDĐH có nhiều giải thưởng $\mathrm{NCKH}$, có nhiều bằng sáng chế và giải pháp hữu ích trong nước và quốc tế. Mạng lưới doanh nghiệp hợp tác hiệu quả. Đặc biệt, nhiều kết quả nghiên cứu của giảng viên, sinh viên và cựu sinh viên đã đã phát triển hình thành một số doanh nghiệp spin-off. Tuy nhiên, các đơn vị này vẫn còn nhiều hạn chế về quy mô đào tạo sau đại học, trao đổi giảng viên và sinh viên, bài giảng điện tử và mức độ tương tác về học thuật giữa sinh viên và với giảng viên còn hạn chế. Trong đó, đối với tiêu chí cuối cùng vừa nểu, nhiều trường còn chưa có chính sách triển khai một cách chính thức và thậm chí chưa có công cụ để đo đếm và quản lý.

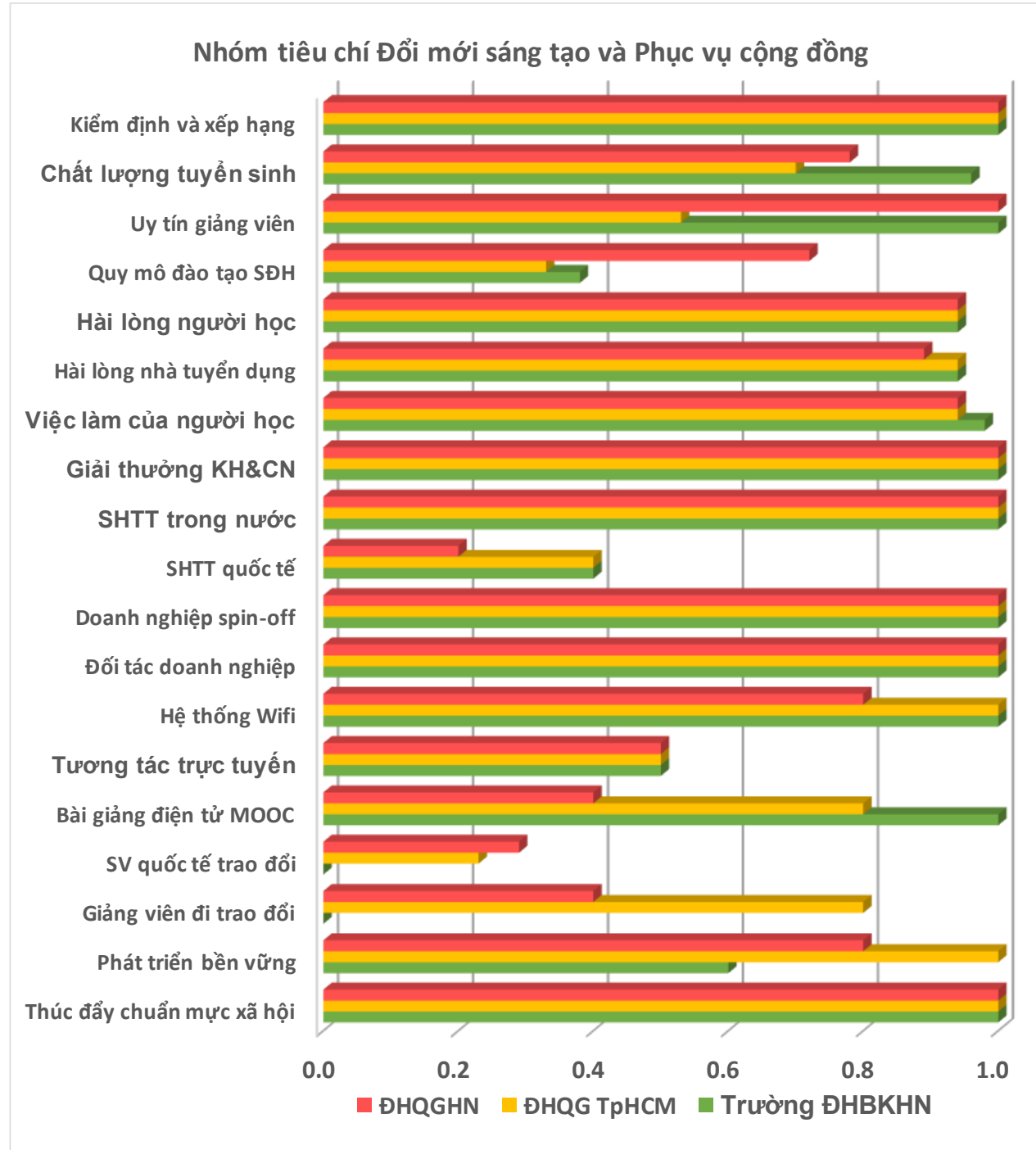

Hình 3. Kết quả đối sánh chuẩn hóa theo các mốc chuẩn đại học top 300 châu Á đối với các nhóm tiêu chuẩn đại học đổi mới sáng tạo và phục vụ cộng đồng của Bộ tiêu chí UPM cho ĐHQGHN, ĐHQG TpHCM và Trường ĐHBKHN. 
Đối với nhóm tiêu chí quản trị chiến lược và tiếp cận đào tạo khởi nghiệp và kỹ năng số (hình 4), các CSGDĐH này đã quan tâm cập nhật, điều chỉnh chiến lược và kế hoạch theo định hướng nghiên cứu, đổi mới sáng tạo và khởi nghiệp, quan tâm ứng dụng CNTT để xây dựng nền tảng cho đại học thông minh; thực hiện kiểm định chất lượng trong nước và quốc tế. Đây là các CSGDĐH tiên phong áp dụng tiếp cận CDIO trong việc điều chỉnh chuẩn đầu ra của chương trình đào tạo và xây dựng các chương trình đào tạo mới gắn với các công nghệ và ngành nghề 4.0. Đồng thời với việc đào tạo năng lực học tập suốt đời cho sinh viên, các trường cũng đã quan tâm xây dựng và triển khai các chương trình đào tạo ngắn hạn, phục vụ nhu cầu học tập suốt đời của cộng đồng. Tuy nhiên, kết quả thực hiện nhóm tiêu chí này vẫn còn nhiều hạn chế. Mặc dù quy định $1982 / \mathrm{Q} Đ-T T g$ và $1665 / \mathrm{Q} Đ-T T g$ của Thủ tướng Chính phủ đã có quy định về kỹ năng và năng lực khởi nghiệp, nhưng hầu như vẫn chưa đề cập trong chuẩn đầu ra của các CTĐT. Hiện nay, kiến thức khởi nghiệp mới được truyền thụ thông qua các câu lạc bộ hoặc ngoại khóa. Cho đến nay, các trường vẫn đang ở giai đoạn chuẩn bị nội dung chương trình của môn học này..

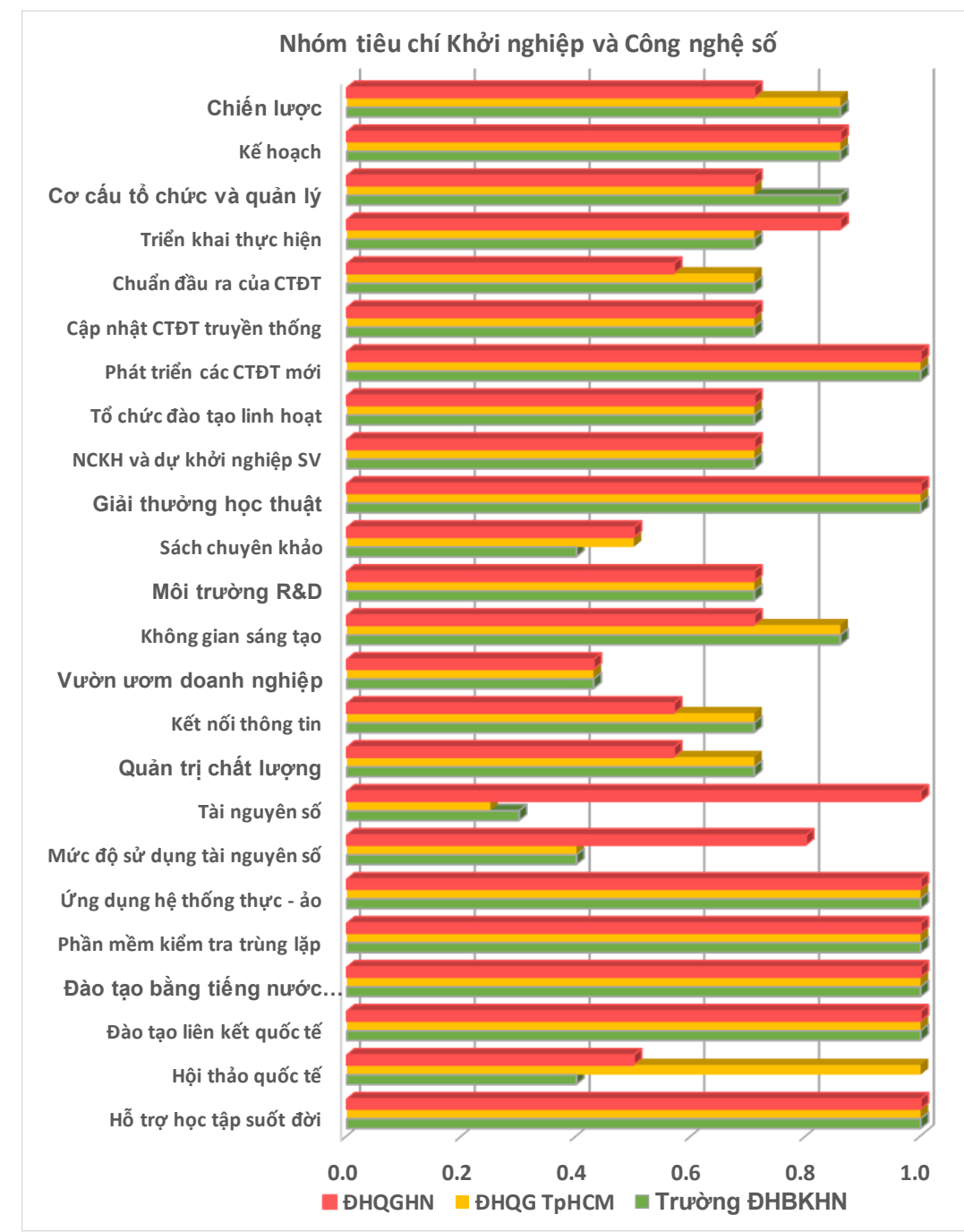

Hình 4. Kết quả đối sánh chuẩn hóa theo các mốc chuẩn đại học top 300 châu Á đối với các nhóm tiêu chuẩn quản trị chiến lược và đáp ứng CMCN 4.0 của Bộ tiêu chí UPM cho ĐHQGHN, ĐHQG TpHCM và Trường ĐHBKHN. 
Ngay cả đối với kỹ năng số - một đặc trưng và yêu cầu cốt lõi của thời đại $\mathrm{CMCN} 4.0$ - cũng chậm được tích hợp vào CTĐT mới. Môn học Tin học cơ sở truyền thống và cũ kỹ vẫn được được tiếp tục giảng dạy, mới có một vài CSGDDH như Trường Đại học Công nghệ (ĐHQGHN) đang chuẩn bị thay đổi bằng môn học Giới thiệu về công nghệ thông tin và kỹ năng số.

Mức độ mở của $\mathrm{CTĐT} \mathrm{và} \mathrm{tính} \mathrm{liên} \mathrm{ngành}$ chưa đạt yều cầu. Nói chung, các chương trình còn mang nặng tính đơn ngành, khu trú và giới hạn ở từng khoa. Tổ chức đào tạo chưa linh hoạt, ngay cả phương thức đào tạo theo tín chỉ vẫn chưa được áp dụng toàn diện và triệt để. Thực tế này còn khác xa các nội dung đã mô tả trong mô hình 4-QUAD và mô hình SMART.

Hệ sinh thái đổi mới sáng tạo đã được hình thành với hệ thống phòng thí nghiệm nghiên cứu và triển khai $(R \& D)$ và các không gian sáng tạo chung, các trung tâm hỗ trợ khởi nghiệp. Tuy nhiên, đối với nhóm tiêu chí này, các trường còn cần phải quan tâm xây dựng các vườn ươm doanh nghiệp và phát huy hiệu quả hoạt động của các không gian sáng tạo. Đặc biệt, cần phát triển số lượng và chất lượng của các tài nguyên số nội sinh, kiến tạo để cả giảng viên và sinh viên đều là người biển soạn và sản xuất học liệu số; tăng cường mức độ truy cập, sử dụng tài nguyên số và đo lường, quản trị được quá trình sử dụng.

\section{Kết luận}

Các đặc trưng và mô hình đại học thích ứng CMCN 4.0 đã được khái quát. Trên cơ sở đó, mô hình đại học SMARTI đã được đề xuất cho các CSGDĐH Việt Nam. Theo đó, trong giai đoạn hiện nay đại học Việt Nam vừa phải thúc đầy phát triển vai trò của đại học thế hệ thứ ba vừa phải thích ứng với cuộc $\mathrm{CMCN}$ 4.0. Mô hình phù hợp là mô hình đại học thông minh định hướng đồi mới sáng tạo. Trong đó, đổi mới sáng tạo là triết lý, mục tiêu và phương thức tạo ra giá trị gia tăng, là động lực cho sự phát triển và thịnh vượng của quốc gia; còn thông minh là phương thức và điều kiện tổ chức thực hiện dựa vào các tiến bộ của công nghệ 4.0. Quan điểm đó được thể hiện trong chiến lược phát triển, sứ mệnh, tầm nhìn và các hoạt động của các CSGDĐH trong thời kỳ mới. Bộ tiêu chuẩn UPM có thể hỗ trợ để xây dựng và quản trị chiến lược phát triển đó. Thông qua các tiêu chí, mốc chuẩn và trọng số trong bộ tiêu chuẩn, UPM có thể hướng dẫn các nhiệm vụ mà các CSGDĐH nên thực hiện, mức độ ưu tiên và chỉ tiêu cần đạt của các nhiệm vụ đó.

Trong thời gian trước mắt, cùng với việc đề xuất 53 hoạt động khá toàn diện, UPM chỉ ra một số tiêu chí cơ bản, có trọng số và mốc chuẩn phù hợp mà các CSGDĐH cần ưu tiên thực hiện. Đó là việc xây dựng và phát triển hệ sinh thái đại học đổi mới sáng tạo và khởi nghiệp có đội ngũ giảng viên trình độ và uy tín cao, thu hút được nhiều sinh viên giỏi; thu hút được nhiều kinh phí hoạt động KHCN, công bố được nhiều bài báo có chất lượng tốt, đăng ký và vốn hóa được nhiều sáng chế trong nước và quốc tế, đặc biệt phát triển được nhiều doanh nghiệp khởi khởi nghiệp. Hệ sinh thái đại học đổi mới sáng tạo cũng cần có môi trường nghiên cứu $R \& D$ và hỗ trợ khởi nghiệp tốt, có hạ tầng CNTT thông minh và hiệu quả. Cùng với nỗ lực quốc tế hóa, các CSGDĐH cần quan tâm đến các hoạt động phục vụ cộng đồng theo các nội hàm mới. Đó vừa thể hiện năng lực gia tăng giá trị vừa là phương thức để thúc đẩy các chuẩn mực xã hội và giá trị nhân văn.

Bộ tiêu chuẩn UMP đã được áp dụng thử nghiệm cho ba CSGDĐH đa lĩnh vực hàng đầu của Việt Nam. Các số liệu trên đây mới chỉ là kết quả khảo sát và quan điểm đánh giá của nhóm nghiên cứu, nhưng về cơ bản phản ánh đúng tình hình hoạt động của các đại học thuộc tốp 300 châu Á. Các áp dụng thử dụng thử nghiệm cho các trường đại học đơn lĩnh vực và khối khoa học xã hội nhân văn đang được tiếp tục hoàn thiện.

\section{Lời cảm ơn}

Công trình nghiên cứu này được tài trợ bởi Chương trình KH\&CN về Khoa học Giáo dục cấp quốc gia với đề tài: Nghiên cứu mô hình trường đại học đáp ứng $\mathrm{CMCN} 4.0$ ("Đại học 4.0”) mã số KHGD/16-20.ĐT.007. 


\section{Tài liệu tham khảo}

[1] Michael A. Peters, Global university rankings: Metrics, performance, governance, Educational Philosophy and Theory, 51(1) (2019).

DOI:10.1080/00131857.2017.1381472

[2] Nguyen Huu Thanh Chung, Vo Dinh Hieu, Ngo Manh Dung, Scientific Research Productivity and Quality of Vietnamese Higher Education Institutions Analysis Based on Integrated Database of Web of Science and Scopus, VNU Journal of Science: Policy and Management Studies, 35(4) (2019) 24-37. DOI: 10.25073/25881116/vnupam.4201 (in Vietnamese).

[3] Nguyen Huu Duc, Nguyen Huu Thanh Chung, Nghiem Xuan Huy, Mai Thi Quynh Lan, Tran Bich Lieu, Ha Quang Thuy, Nguyen Loc, Towards the Higher Education 4.0 - Characteristics and Criteria. VNU Journal of Science: Policy and Management Studies 34(4) (2018) 1-28. DOI: 10.25073/2588-1116/vnupam.4160.(in Vietnamese)

[4] C.B.J. Ong, T.M.N. Nguyen, The 4Cs Framework to Transform Higher Education Institution as an Innovation Producing Ecosystem, International Workshop "Creativity Development and Opportunities for Business and Startup Ideas". Hanoi, 11-12,8/2017.

[5] J.G. Wissema, Towards the third generation university. Managing the university in transition. Edward Elgar, Cheltenham, United Kingdom (2009).

[6] M. Guerrero-Cano, D. Kirby, D. Urbano, A literature review on entrepreneurial universities: An institutional approach, Working paper presented at the 3rd Conference of Precommunications to Congresses, Business Economic Department. Autonomous University of Barcelona. Barcelona, June 2006. https://www.researchgate.net/publication/2286573 19 (accessed 11 June 2019).

[7] Li Weiming, Li Chunyan, Du Xiaohua, Tens year of Entrepreneurship Education at Chiness Universities: Evolution, Problems and System Building, Chiness Education \& Society 49 (3) (2016) 198-216,

DOI: $10.1080 / 10611932.2016 .1218250$.
[8] Framing Malaysian Higher Education - Future Proof Talents, Ministry of Higher Education Malaysia, 2018.

[9] L. Aida Velasco, Entrprenurship education in Philippnes, DLSU Business \& Education Review, 22 (2013) 1.

[10] Malaysia (2018), Redesigning Malaysia higher education,

https://www.thestar.com.my/news/education/2018 /05/06/redesigning-malaysias-higher-educationsystem/. (accessed 20 October 2019).

[11] Fehmida Hussain, E-learning 3.0 = E-learning 2.0 + Web.3.0, IADIS International Conference on Cognition and Exploratory Learning in Digital Age (CELDA 2012), p.11.

[12] Vietnam National University, Hanoi: Guidelines for implementing research-oriented university criteria (2013).

https://vnu.edu.vn/upload/vanban/2013/10/08/120 6-Huong-dan-ve-cac-tieu-chi-truong-daihocnghien-cuu..pdf (in Vietnamese).

[13] QS STAR, https://www.topuniversities.com/qsstars/qs-starsmethodology. (accessed 20 December 2019)

[14] U-Multirank: Compare University and Colleges Rankings, https://www.umultirank.org. (accessed 20 December 2019)

[15] Allan Gibb, Exploring the synergistic potential in entrepreneurial university development: towards the building of a strategic framework, Annals of Innovation \& Entrepreneurship 3 (2012) 16742. DOI: 10.3402/aie.v3i0.16742

[16] Guide to AUN-QA Assessment, ASEAN University Network, 2015.

[17] https://www.topuniversities.com/universityrankings/asian-university-rankings/2020. (accessed 20 December 2019)

[18] Topuniversities, https://www.topuniversities.com/universityrankings/world-university-rankings/2020; https://www.timeshighereducation.com/worlduniversity-rankings/2020/worldranking\#!/page/0/length/25/locations/VN/sort_by/ rank/sort_order/asc/cols/stats. (accessed 20 December 2019). 